\title{
Article \\ Investigation of LINC00493/SMIM26 Gene Suggests Its Dual Functioning at mRNA and Protein Level
}

\author{
Daria Konina ${ }^{1,2, *}$, Peter Sparber ${ }^{2}\left(\mathbb{D}\right.$, Iuliia Viakhireva ${ }^{2}$, Alexandra Filatova ${ }^{2, *}$ and Mikhail Skoblov ${ }^{2}(\mathbb{D}$ \\ 1 Moscow Institute of Physics and Technology, Phystech School of Biological and Medical Physics, \\ 141701 Dolgoprudny, Russia \\ 2 Research Centre of Medical Genetics, Laboratory of Functional Genomics, 115478 Moscow, Russia; \\ psparber93@gmail.com (P.S.); yuliya-vyakhireva@yandex.ru (I.V.); mskoblov@gmail.com (M.S.) \\ * Correspondence: darya.konina@phystech.edu (D.K.); maacc@yandex.ru (A.F.)
}

Citation: Konina, D.; Sparber, P.; Viakhireva, I.; Filatova, A.; Skoblov, $\mathrm{M}$. Investigation of

LINC00493/SMIM26 Gene Suggests Its Dual Functioning at mRNA and Protein Level. Int. J. Mol. Sci. 2021, 22, 8477. https://doi.org/10.3390/ijms 22168477

Academic Editor: Luca Agnelli

Received: 19 July 2021

Accepted: 5 August 2021

Published: 6 August 2021

Publisher's Note: MDPI stays neutral with regard to jurisdictional claims in published maps and institutional affiliations.

Copyright: (c) 2021 by the authors. Licensee MDPI, Basel, Switzerland. This article is an open access article distributed under the terms and conditions of the Creative Commons Attribution (CC BY) license (https:/ / creativecommons.org/licenses/by/ $4.0 /)$.

\begin{abstract}
The amount of human long noncoding RNA (lncRNA) genes is comparable to proteincoding; however, only a small number of lncRNAs are functionally annotated. Previously, it was shown that lncRNAs can participate in many key cellular processes, including regulation of gene expression at transcriptional and post-transcriptional levels. The lncRNA genes can contain small open reading frames (sORFs), and recent studies demonstrated that some of the resulting short proteins could play an important biological role. In the present study, we investigate the widely expressed lncRNA LINC00493. We determine the structure of the LINC00493 transcript, its cell localization and influence on cell physiology. Our data demonstrate that LINC00493 has an influence on cell viability in a cell-type-specific manner. Furthermore, it was recently shown that LINC00493 has a SORF that is translated into small protein SMIM26. The results of our knockdown and overexpression experiments suggest that both LINC00493/SMIM26 transcript and protein affect cell viability, but in the opposite manner.
\end{abstract}

Keywords: LINC00493; SMIM26; long noncoding RNA; lncRNA; sORF; MTT; wound healing

\section{Introduction}

Advances in sequencing techniques revealed the transcription of non-coding regions of the genome which correspond to different groups, such as long noncoding RNA genes, small noncoding RNA genes, pseudogenes and immunoglobulin/T-cell receptor gene segments. Long noncoding RNAs (lncRNAs) are transcripts with lengths more than 200 nucleotides that are not translated into functional proteins. According to the GENCODE project (release 38) [1], the human genome contains 17,944 lncRNA genes. Data from the FANTOM CAT project revealed 27,919 human lncRNA loci [2]. The number of lncRNA genes is comparable to the number of protein-coding genes $(19,954)$. However, lncRNAs make up only $0.03-0.20 \%$ of total RNA mass in the cell, whereas mRNAs make up $3-7 \%$ of it [3].

Initially thought to be transcriptional noise, several lncRNAs were discovered to be involved in gene expression regulation processes and affect cellular functions [4]. LncRNAs realize their functions through different intermolecular interactions: formation of a DNAlncRNA triplex, formation of an lncRNA-RNA duplex and formation of an lncRNA-protein or lncRNA-chromatin complex [5]. These complexes may affect gene expression at the transcriptional [6-9] or post-transcriptional levels [10-12] and thus affect cellular phenotype.

Many IncRNAs are expressed in a tissue-specific manner, and their effect can vary in different cell types [13]. Moreover, lncRNAs' expression can be altered in different pathological conditions, and their dysregulation may play an important role in disease progression [14]. To date, the IncRNADisease2.0 database contains entries about 19,166 lncRNAs associated with 529 diseases [15], including heart failure, cerebral injury, hypertension, acute kidney injury and cancer [16-18]. Genome-wide association studies (GWAS) indicate 
that lncRNA genes are enriched for trait- or disease-linked polymorphisms. Over $90 \%$ of all GWAS hits lie outside of known coding genes $[19,20]$.

LncRNAs have an average length of about $3 \mathrm{~kb}$ and could contain up to 120 small open reading frames (sORFs) with a median of six sORFs per lncRNA. Recent studies proved that about 10,000 lncRNA genes in the mammalian genome contain sORFs less than $300 \mathrm{nt}$ in length [21-23]. These sORFs could be translated into short peptides with key biological functions [24]. The presence of small peptides encoded by lncRNAs suggests that in some cases lncRNAs may have a dual function, or that the observed biological effect is contributed by the small protein, which means that this class of genes should be reclassified as protein coding [25-27].

In the present study, we investigate the widely expressed lncRNA LINC00493. We determine the structure of the LINC00493 transcript, its localization, protein-coding potential and its influence on cell physiology. Our data demonstrate the cell-type-specific role of LINC00493. During our work, LINC00493 was predicted to contain a sORF that could translate a small protein-SMIM26. We collected and described all the existing data on this protein. Using knockdown and overexpression experiments, we obtain data suggesting that both LINC00493/SMIM26 transcript and protein affect cell viability, but in the opposite manner.

\section{Results}

\subsection{LINC00493 Transcript Structure}

The LINC00493 gene was predicted through the ENCODE project. The UCSC Genome Browser [28] shows that LINC00493 is located on human chromosome 20p11.23 and consists of two or three exons, according to mRNA and EST sequence data from RefSeq and Ensembl databases. In contrast to the protein-coding genes, the lncRNA gene annotations tend to have poorly defined boundaries, because of weak conservation, low and tissuespecific expression and lack of characteristic hallmarks of transcription initiation and termination [29]. Therefore, to define the exact structure of the LINC00493 transcript we performed reverse transcription (RT)-PCR and rapid amplification of cDNA ends (RACE) analysis on total RNA from HEK293T, HeLa cell lines and human primary skin fibroblasts. RT-PCR analysis revealed that the LINC00493 transcript consists of two exons and RACE showed the exact $5^{\prime}$ and $3^{\prime}$ cDNA ends (Figure $1 \mathrm{~A}$ ).

According to the Ensembl database, there are two LINC00493 isoforms, ENST00000411646.1 and ENST00000435844.3, which differ by three nucleotides at the beginning of the second exon. Our RT-PCR analysis confirmed that LINC00493 has two isoforms, expressed in all analyzed cell lines. The total length of the short and long isoforms was 500 and $497 \mathrm{bp}$, respectively. The nucleotide sequences of short and long isoforms were deposited into GenBank under accession numbers MW979249 and MW979250. The difference in the sequencing signal suggests that the major long isoform is expressed at an approximately 3-fold higher level than the minor one.

\subsection{LINC00493 Is Widely Expressed in Human Tissues and Cell Lines}

To identify LINC00493 expression profile, we provided analysis of the FANTOM5 and GTEx expression data. We observed that LINC00493 is highly expressed in most human cell lines and tissues. An expression profile of LINC00493 in 889 human samples from FANTOM5 classified this gene as a housekeeping gene [30]. We confirmed the high widespread expression level of this transcript using RT-qPCR analysis of 11 human cell lines, as well as human primary skin fibroblasts (Figure 1B). The highest expression level was observed in A549, MCF7 and HEK293T cell lines. 
A

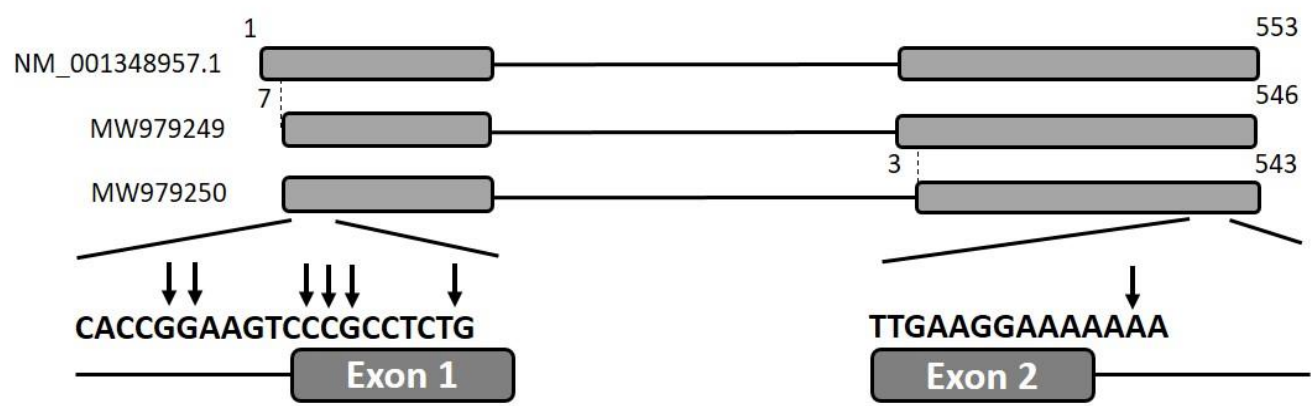

B

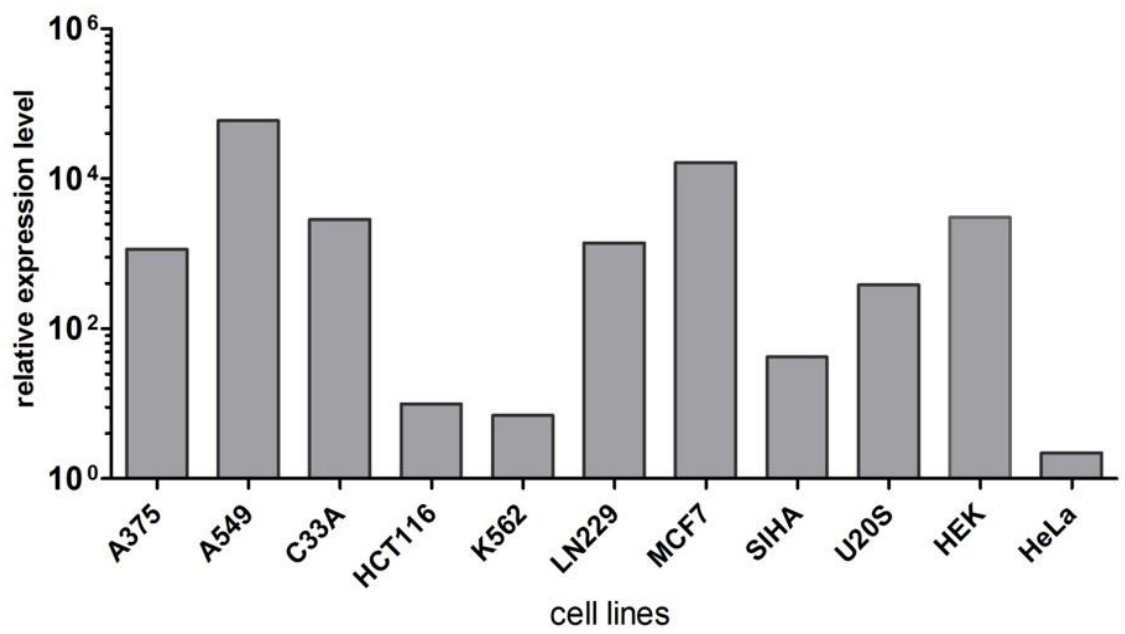

C

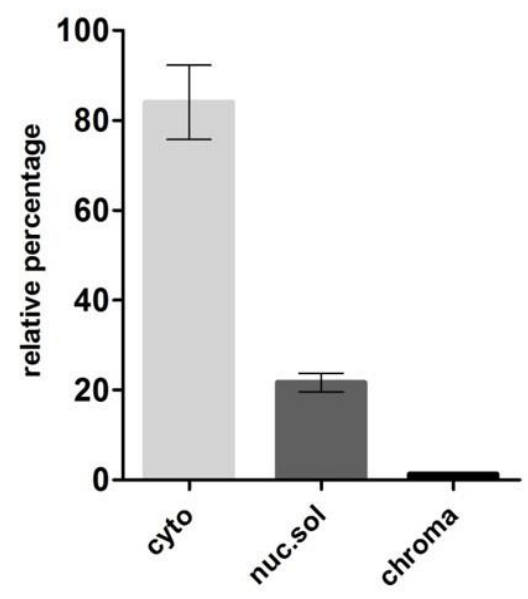

Figure 1. Analysis of the structure and expression of the LINC00493 transcript. (A) Scheme of the LINC00493 gene (according to RefSeq NM_001348957.1 sequence). Results of $5^{\prime}$ and $3^{\prime}$ RACE analysis are presented under the scheme. The vertical arrows represent the genomic position of exact $5^{\prime}$ and $3^{\prime}$ ends. Nucleotide numbering was based on reference sequence NM_001348957.1 (B) Relative expression of LINC00493 transcript in 11 human cell lines was detected by RT-qPCR. (C) Subcellular localization of LINC00493 was detected by qPCR of RNA isolated from cytoplasmic (cyto), nuclear-soluble (nuc.sol) and chromatin-bound (chroma) fractions of HEK293T cells. The error bars represent SEM (standard error mean).

\subsection{Cytoplasmic Localization of LINC00493}

LncRNA subcellular localization is closely related to its biological function. Some IncRNAs play a role in a transcriptional regulation through their interaction with chromatin, while others are found in the cytoplasm and affect the post-transcriptional control of gene expression or could be translated into small peptides. We investigated the subcellular localization of the LINC00493 transcript using the soft lysis method. RNA was isolated from cytoplasmic, nuclear and chromatin-bound fractions of cells. To determine the level of the investigated transcript in each fraction we performed RT-qPCR. Our analysis revealed that the LINC00493 transcript is localized predominantly in cytoplasm (Figure 1C). This result suggests that the function of the LINC00493 transcript is not related to the transcription regulation and chromatin binding. The observed results highlight similarities between the investigated lncRNA and mRNAs, such as sequence length, high expression level and accumulation in the cytoplasm.

\subsection{Knockdown of LINC00493 Affects Cell Growth in a Cell-Type-Specific Manner}

To determine the function of LINC00493, we analyzed previously published CRISPRibased data for functional long noncoding RNA loci in human cells [13] and discovered that LINC00493 modified cell growth in a cell-type-specific manner. To confirm the cell-typespecific role of LINC00493, we performed knockdown experiments using RNA interference in three human cell lines: HEK293T, A375 and MDA-MB-231. 
LINC00493 knockdown efficiency was about 60-70\% (Figure 2A). After knockdown, cell proliferation was measured by MTT assay, and cell migration was examined using wound-healing assay. We revealed that LINC00493 knockdown reduced cell viability in HEK293T and A375 cell lines, while the opposite effect was observed in MDA-MB-231 (Figure 2C). Thus, knockdown experiments confirmed that downregulation of LINC00493 affected cell proliferation activity in a cell-type-specific manner. On the other hand, woundhealing assay revealed that LINC00493 knockdown did not affect cell migration (Figure 2B,D).

A

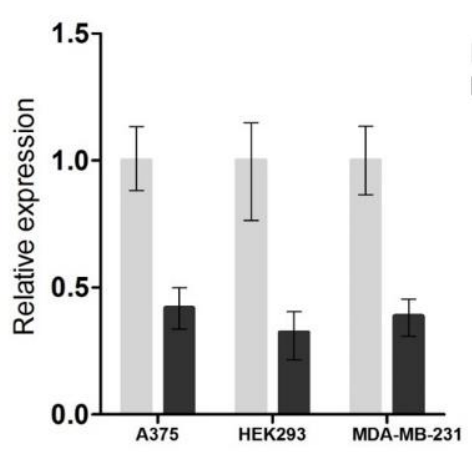

B

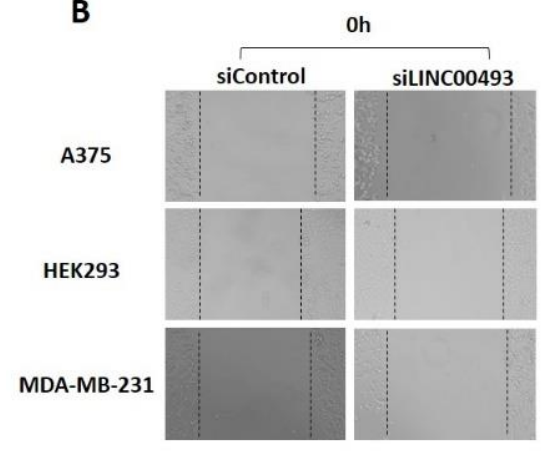

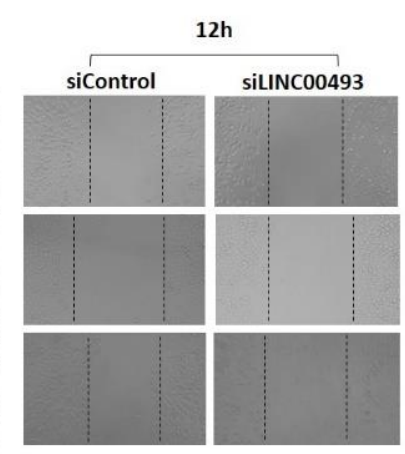
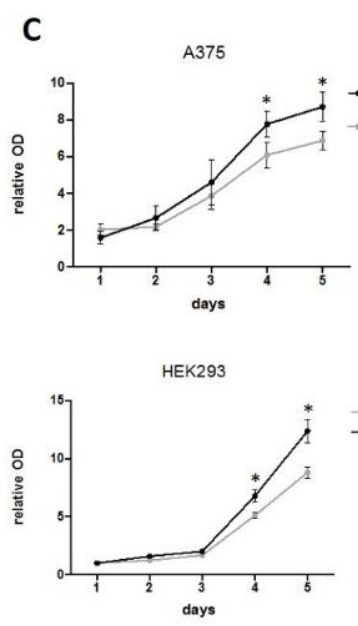

MDA-MB-231

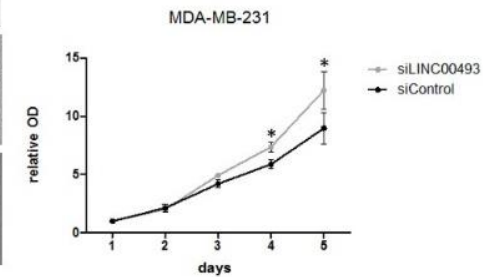

D
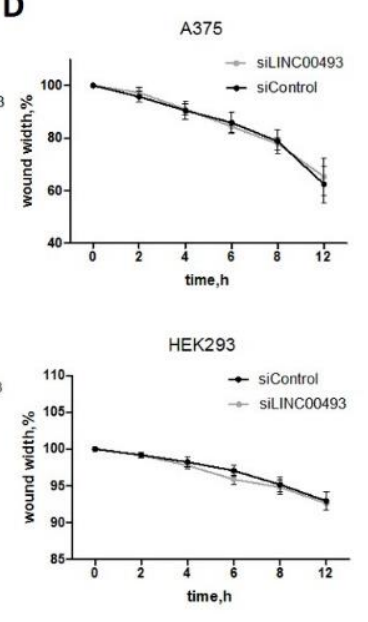

MDA-MB-231

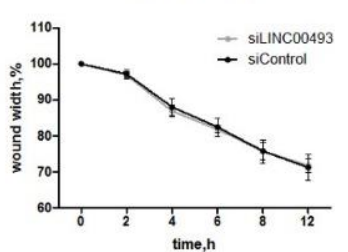

Figure 2. LINC00493 knockdown has a cell-type-specific effect. (A) LINC00493 knockdown efficiency in A375, HEK293T and MDA-MB-231 cell lines. (B) The migration ability of A375, HEK293T and MDA-MB-231 cells after transfection of siLINC00493 and siControl was measured by wound-healing assay. Representative images of wound-healing experiments are shown. (C) MTT assay reveals the effect of LINC00493 knockdown in 3 cell lines. Relative optical density value of A375, HEK293 and MDA-MB-231 cells with LINC00493 knockdown and control cells in the MTT assay. (D) Summary graph showing typical wound-healing rates by A375, HEK293 and MDA-MB-231 cells after LINC00493 knockdown. Error bars represent the mean \pm SEM (standard error mean) of three independent experiments. ${ }^{*} p<0.01$, vs. control (according to Mann-Whitney U test).

\subsection{Small Protein Is Translated from LINC00493 RNA}

According to the Human Protein Atlas [31], LINC00493 contains a small open reading frame that could be translated to a 94/95-amino-acid protein-SMIM26. Using GWIPSviz [32] and Trips-Viz [33], which provide ribosome profiling data, we confirmed that LINC00493 has a strong ribosome association in the predicted sORF region (Figure 3C). The predicted secondary and tertiary structures of SMIM26, constructed using an improved predictor of protein structure [34], showed that the protein contains two alpha helixes; one of them is supposed to be a transmembrane domain (Figure 3B,D). A number of tools (Phobius, SPOCTOPUS, MEMPACK) predict that SMIM26 is localized in the membrane. Despite this fact, the Human Protein Atlas immunocytochemistry analysis revealed that this protein is localized mainly in the nucleoplasm and partially in the cytosol [31]. However, the function of the protein remains unknown. Comparative analysis of amino-acid and nucleic sequences of LINC00493 reveals that the gene is evolutionarily conserved among mammals both at the RNA and protein level (Figure 3A). This fact supports a potential 
functional role for SMIM26, while the influence of this protein on cell migration and viability was not shown previously.

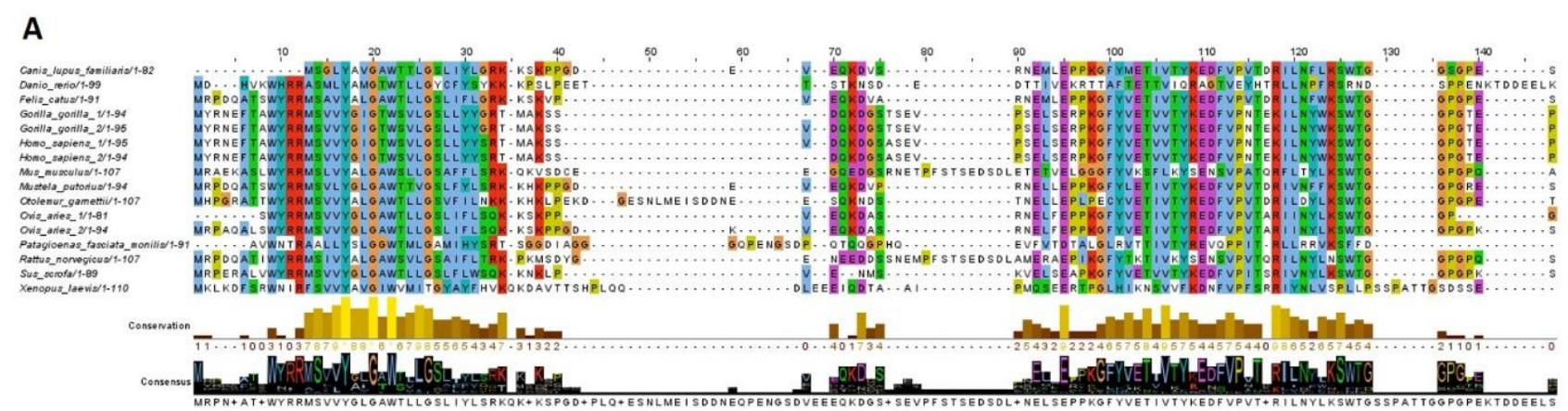

B

Sequence: MYRNEFTAWYRRMSVVYGIGTWSVLGSLLYYSRTMAKSSVDQKDGSASEVPSELSERPKGFYVETVVTYKEDFVPNTEKILNYWKSWTGGPGTEP

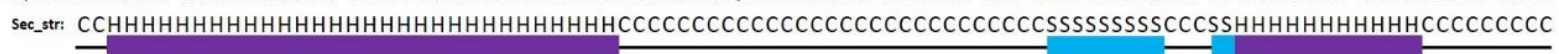

C

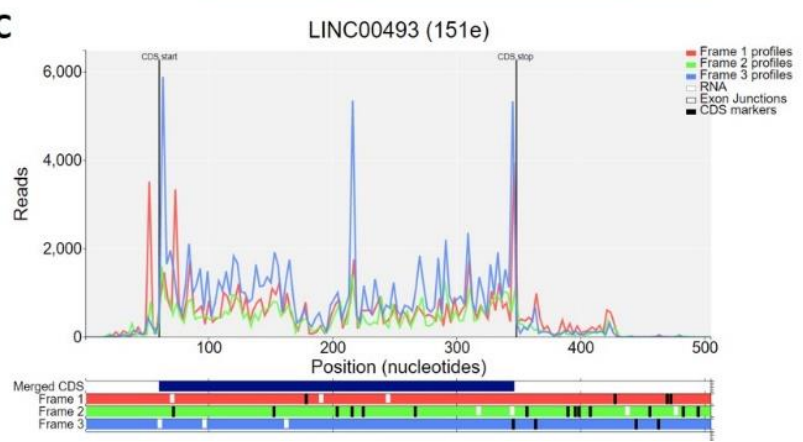

D

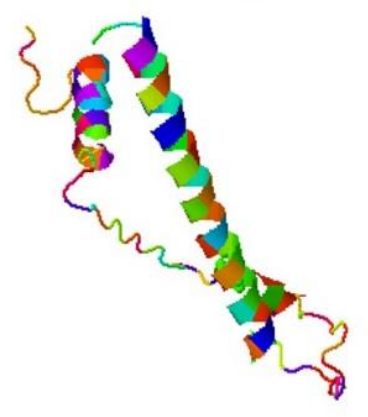

Figure 3. Analysis of the structure of the SMIM 26. (A) Multiple-species alignment of the amino acid sequences of the LINC00493-encoded small protein SMIM26. (B) Predicted secondary structure (H: helix; S: strand; C: coil) of SMIM26. (C) Distribution of the RPF reads in the LINC00493-ORF. (D) Predicted 3D structure of SMIM26.

\subsection{SMIM26 Protein Affects Cell Viability}

Data from knockdown experiments revealed that the LINC00493 gene is important for cell viability. However, it remains unclear whether the observed effect is associated with small protein or with the RNA itself. To investigate separately the effect of SMIM26 protein and the LINC00493 transcript on cell viability, we cloned a full-length LINC00493 cDNA into pcDNA3.1-GFP vector (pcDNA3.1) and obtained LINC00493_WT plasmid. Next, we mutated the SMIM26 start-codon by site-directed mutagenesis to prevent the translation of small protein and obtained the LINC00493_MUT plasmid. Wild-type and mutant constructs, along with an empty pcDNA3.1, were transfected into A375 and HEK293T cells and cell viability was measured using the MTT test. The expression of LINC00493 was increased about a thousand-fold times by qPCR (Figure 4A).

Interestingly, overexpression of WT LINC00493 did not influence the number of cells, while overexpression of LINC00493 with a mutated start-codon demonstrated increased cell viability (Figure 4B,C). This observation suggests that, even in the absence of SMIM26 protein translation, the LINC00493 transcript itself has an effect on cell viability. However, the difference between WT and MUT LINC00493 overexpression indicates that SMIM26 protein could also affect cell viability, but in the opposite manner. 
A

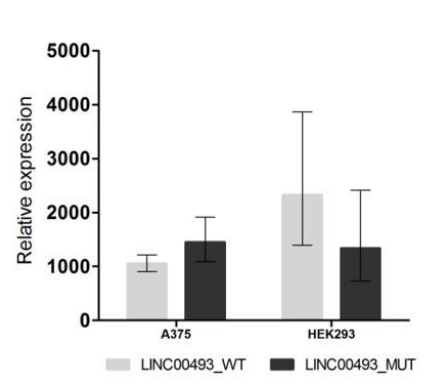

B

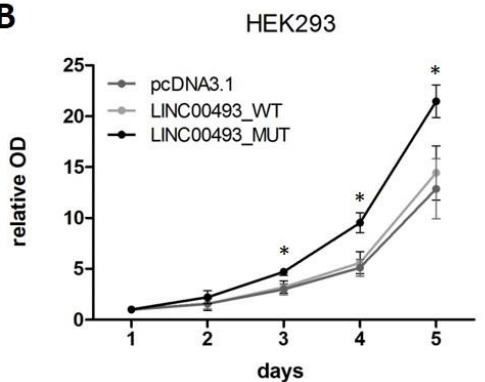

C

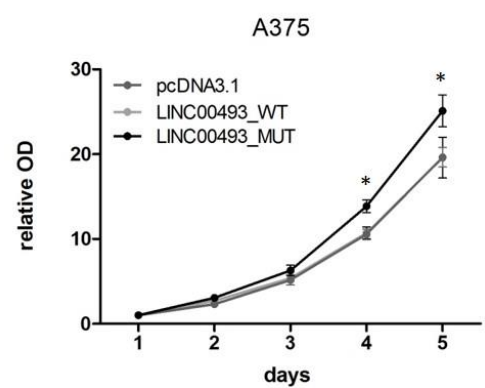

Figure 4. Influence of LINC00493/SMIM26 overexpression on cell viability. (A) LINC00493_WT and LINC00493_MUT overexpression efficiency in A375 and HEK293 cell lines. (B,C) Relative optical density value of HEK293 and A375 cells treated by LINC00493_WT, LINC00493_MUT and control cells in the MTT assay. Cells with overexpression of mutated LINC00493 showed higher viability than those transfected with WT LINC00493 or empty pcDNA3.1 vectors. Error bars represent the mean $\pm \mathrm{SEM}$ (standard error mean) of three independent experiments. ${ }^{*} p<0.01$, vs. control (according to Mann-Whitney U test).

\section{Discussion}

The human genome contains 30,000 lncRNA genes [2] and only a small number of them have experimentally defined function, although FANTOM5 computational analysis revealed that more than half of human lncRNA loci are functionally implicated [2]. An increasing number of studies are focused on IncRNA function, including both highthroughput $[13,35]$ and single-lncRNA study $[6,27,36]$ approaches. At the same time, recent studies revealed that about 10,000 lncRNA genes in the mammalian genome contain small ORFs ( $<100$ amino acids) [21-23], and the resulting short proteins could be functional [24].

In the present study, we analyze the structure, expression profile, function and proteincoding potential of LINC00493 IncRNA. We show that LINC00493 is a widely expressed transcript that has two isoforms differing by three nucleotides of the second exon. We reveal that the LINC00493 transcript is localized predominantly in the cytoplasm. The results suggest that the function of this transcript is not related to the transcription regulation and chromatin binding. Moreover, using publicly available Ribo-seq data presented in the GWIPS-viz [32] and Trips-Viz [33], we reveal a high translation signal within the LINC00493 small open reading frame (Figure $4 \mathrm{C}$ ).

These observations are consistent with the previously conducted analysis of Mukherjee et al. [37]. Using a comprehensive study of molecular features (such as transcription, splicing, degradation, localization and translation) for human coding and noncoding transcripts, authors grouped human lncRNA genes based on similar RNA metabolism profiles. Mukherjee et al. assigned the LINC00493 gene to the $\mathrm{c} 1$ gene class, which has the greatest similarity to mRNA. Moreover, the authors demonstrated that LINC00493 contained a highly translated ORF with peptide evidence. Together, these data suggest that the LINC00493 gene is a protein-coding gene. Further, in the GENCODE human genome current release (GRCh38.p13) [1], the lncRNA gene LINC00493 was re-annotated to the SMIM26 gene, which encodes 94/95-amino-acid small integral membrane protein 26. Moreover, the immunocytochemistry analysis provided by the Human Protein Atlas project [31] revealed that this small protein is present in the cells and is localized mainly in the nucleoplasm.

A recent study of Fouzia Yeasmin et al. [38] confirmed the translation of LINC00493 by using luciferase reporter assays and Western blotting analysis. It was shown that the SMIM26 protein interacts with many mitochondrial proteins. In addition, the authors demonstrated mitochondrial localization of the SMIM26 protein; these data do not correspond to those presented by the Human Protein Atlas project. Meanwhile, Fouzia Yeasmin et al. localization data are supported by the Shan Zhang at al. [39] research, which, using bioinformatical approach and immunofluorescence analysis, discovered that 
SMIM26 is localized in mitochondria. However, any function of this protein was not previously described.

During the present study, we showed that the LINC00493/SMIM26 gene is evolutionarily conserved among mammals both at the RNA and protein level. This fact supports a potential functional role for the LINC00493/SMIM26 gene. In addition, analysis of the nucleotide variants from the Genome Aggregation Database (gnomAD) v2.1.1 [40] showed that protein loss-of-function variants in this gene are rare in a heterozygous state and absent in a homozygous state. These observations cannot exclude the important functional role of the SMIM26 gene and its involvement in the development of human diseases. To determine the potential effect of LINC00493/SMIM26 on cell physiology, we performed knockdown and overexpression experiments.

We show that knockdown of LINC00493/SMIM26 influences cell viability in a celltype-specific manner; it decreases cell viability in HEK293T and A375 cells, while it increases cell viability in MDA-MB-231. These results are consistent with the previously obtained data by Liu et al. [13]. The authors used the high-throughput CRISPR interference (CRISPRi) platform to analyze the effect of 16,401 lncRNA loci (including LINC00493) on cell growth phenotype in seven cell lines. According to the Liu et al. data, LINC00493 knockdown reduced the proliferation of HEK and HELA cells, while it caused an increase in the growth rate in MDA-MB-231. In other tested cell lines, knockdown of LINC00493 led to insignificant cellular growth change.

Some studies previously showed the dual function of RNA: coding and intrinsic RNA [41,42]. Thus, it remains unclear whether the observed LINC00493/SMIM26 knockdown effect is associated with small protein or with the RNA itself. To study this, we performed an overexpression of the full-length wild-type LINC00493 transcript and a transcript with a SMIM26 start-codon mutation. We show that even in the absence of SMIM26 protein translation, the LINC00493 transcript itself increases cell viability in HEK293T and A375 cell lines. It allows us to suggest that the LINC00493 transcript has intrinsic function independent of SMIM26 protein. However, the most intriguing observation is the fact that in case of wild-type LINC00493 overexpression, cell viability does not change. This means that in the case of overexpression of SMIM26 RNA and protein, cell viability decreases compared to overexpression of a transcript that is not translated. Thus, we hypothesize that LINC00493/SMIM26, both transcript and protein, affect cell viability, but in the opposite manner. A similar phenomenon, of the opposite effects of RNA itself and the protein encoded by it, was described by Spencer et al. [43]. The authors showed that overexpression of full-length LINC00961 transcript did not influence tubule formation, while overexpression of LINC00961 open reading frame SPAAR increased tubule formation. Moreover, overexpression of a start-codon mutant of the full-length LINC00961 transcript reduced network formation. Thus, Spencer et al. first reported a bi-functional LINC00961/SPAAR locus in cardiovascular research [43].

Our hypothesis of the possible opposite function of the LINC00493/SMIM26 transcript and protein could potentially provide a clue to understanding the tissue-specific effect of this gene, since it could be related to the RNA/protein ratio in each particular cell type. RNA/protein ratio could depend on various factors, including translation efficiency, mRNA and protein stability. Previously, Stevens et al. showed that protein/mRNA ratio between cell lines is highly variable for some genes, despite the fact that for many genes estimated translation efficiency has considerable consistency between cell lines [44]. In addition, the cell-type-specific effect of LINC00493/SMIM26 can be associated with different molecular interactions within different types of cells. Therefore, the phenomenon of the LINC00493/SMIM26 cell-type-specific effect is of interest for further investigation.

As the LINC00493 transcript itself affects cell viability, we analyzed publicly available data to identify the possible molecular partners and cell processes in which this RNA may be involved. Analysis of SPLASH data from starBase v2.0 [45] revealed that the LINC00493 transcript interacts with RNA5-8S5, RNA18S5, RNA18N5, RNA28S5 rRNAs and Leu_tRNA; this highlights its role as a coding RNA. At the same time, analysis of 
LINC00493 RNA-binding proteins revealed that many of them are involved in the regulation of inflammatory protein activity (e.g., TSC22D3, HSP90AB1, SH3BP2, TMEM59 [46-49]) and play an important role in basic cell processes (e.g., NUCKS1, SMG6, DDX41 [50-53]). Analysis of RNA interactome data from the RISE database [54] revealed an interaction of LINC00493 with GTF3C4 (general transcription factor IIIC, polypeptide), which plays an important role in transcription regulation and gene expression.

Additionally, we investigated CLIP-seq data for miRNA-mRNA interactions available in the starBase v2.0 database [45] that showed the interaction of LINC00493 transcript with several miRNAs [55]. Top miRNA interactors are involved in cell migration and invasion regulation pathways (miR-32-5p, miR-153-3p, miR-126-5p, miR-92b-3p [56-60]). Several miRNAs, such as miR-137 [61] and miR-448 [62], have been investigated as potential therapeutic targets in cancer. Moreover, these miRNAs are also involved in inflammatory processes (miR-92b-3p, miR-448 [63,64]). The identified LINC00493 interactions are consistent with an important role of LINC00493 in basic cellular processes and its possible involvement in tumor development. Moreover, we analyzed RNA-seq data from tumor and normal tissues using the GEPIA2 tool [65]. We found that LINC00439 transcript is significantly more strongly expressed in several types of tumors (lymphoid neoplasm diffuse large B-cell lymphoma, pancreatic adenocarcinoma and thymoma) (Supplementary Figure S1).

Thus, our experimental and bioinformatics analysis suggests that the LINC00493/SMIM26 gene plays an important role in cell viability in a cell-type-specific manner, and may play a role in the development of tumors and/or other human diseases. However, more detailed studies of LINC00493 function and its cell-type-specific regulation are required.

\section{Materials and Methods}

\subsection{Bioinformatics Tools}

Nucleotide sequences of the studied gene were found in the following databases: RefSeq release 90 [66], Ensembl release 98 [67] and GENCODE release 38 [1]. Conservation and expression level in various human cell lines and tissues were analyzed using data from the UCSC genomic browser, FANTOM5 [68] and GTEx (Genotype-Tissue Expression) [69] expression data. Nucleotide sequences were analyzed using a BLAST (Basic Local Alignment Search Tool) search of the NCBI NR nucleotide database with standard parameters.

Ribo-seq data presented in the GWIPS-viz [32] and Trips-Viz [33] were used for estimation of single transcripts' coding potential. Protein immunocytochemistry and localization were analyzed using the Human Protein Atlas [31], which maps the human proteins in cells, tissues and organs using an integration of various omics technologies, including antibody-based imaging, mass-spectrometry-based proteomics, transcriptomics and systems biology. Phobius [70], SPOCTOPUS [71] and MEMPACK [72] tools were used to conduct transmembrane topology and signal peptide prediction. An improved protein structure predictor helped us to understand secondary and tertiary structures [34]. The selected predictor used a deep residual network for predicting interresidue orientations, in addition to distances, and a Rosetta-constrained energy-minimization protocol for rapidly and accurately generating structure models.

Analysis of the nucleotide variants was carried out using gnomAD v2.1.1 (Genome Aggregation Database) [73].

Data from starBase v2.0 [45] and RISE database (database of RNA interactome from sequencing experiments) [54] was used for miRNA-RNA and RNA-RNA interactions prediction. To understand the transcript's possible involvement in tumor development, we analyzed RNA-seq data from tumor and normal tissues obtained by TCGA (The Cancer Genome Atlas) and GTEx projects using GEPIA2 tool [65].

\subsection{Cell Culture}

HEK293T (human embryonic kidney 293T cell line), A375 (human melanoma cell line) and MDA-MB-231 (human breast cancer cell line) were cultured in DMEM (PanEco, Russia), 
supplemented with $10 \%$ fetal bovine serum (Biosera, France) at $37{ }^{\circ} \mathrm{C}$ in a humidified atmosphere under $5 \% \mathrm{CO}_{2}$ conditions.

\subsection{RNA Extraction and Reverse Transcription-Quantitative PCR (RT-qPCR)}

Total RNA was extracted using ExtractRNA reagent (Evrogen, Moscow, Russia) according to the manufacturer's instruction. RNA was treated with DNAseI (Thermo Fisher Scientific, Waltham, MA, USA) and reverse transcribed using ImProm-II ${ }^{\mathrm{TM}}$ Reverse Transcription System (Promega, Madison, WI, USA). qPCR experiments were performed using EvaGreen ${ }^{\circledR}$ Dye (Biotium, Fremont, CA, USA). Primers used for amplification of different LINC00493 loci are presented in Table 1. qPCR amplification reactions were run in triplicate for each cDNA sample. LINC00493 expression level was normalized against the mean expression level of 4 housekeeping genes (B2M, HPRT, TFRC, TBP); primers are listed in Table 1.

Table 1. Primer sequences used for amplification of different LINC00493 loci and housekeeping genes; siRNA sequences used for knockdown.

\begin{tabular}{|c|c|}
\hline Title & Sequence \\
\hline Ex1f2 & 5'-TGGCGTACCCATGTATCGAA-3' \\
\hline Ex1r1 & 5'-AAAGCAGTGAGCCCAACACA-3' \\
\hline Prom-f1 & 5'-GACGCCCTCACCGGAAGT-3' \\
\hline Prom-f2 & 5'-GCGGCAGGGACCGCAGC-3' \\
\hline Ex2f1 & 5'-TACAGAAAAGATCCTCAACTAT-3' \\
\hline Ex2r1sh & 5'-TAAATGTTGAACCAAGTCCTG-3' \\
\hline Ex2r21 & 5'-TTGCATATTATTAGTGATTATGTT-3' \\
\hline Add-f1 & 5'-CGAGGCTGGTCTCAAACAC-3' \\
\hline Add-r1 & 5'-CTCCAACCCCAATAATGAAGG-3' \\
\hline Ex1f1 & 5'-CCCGCCTCTGCCGTGGG-3' \\
\hline F3 & 5'-ATAGCCGGACAATGGCGAAG-3' \\
\hline R3 & 5'-TGGGCGTTCAGAGAGTTCAC-3' \\
\hline Clon-F-HindIII & 5'-AAAAAAGCTTCGTGGGCCTGCGAATCGAG-3' \\
\hline Clon-R-XholI & 5'-AAAACTCGAGAACGCAGATAGTTTCCTTCAAG-3' \\
\hline LINC-ATGmut & $\begin{array}{c}\text { 5'-CGAGGCACTCGCTGGCGTACCTTTGTATCGAA } \\
\text { ATGAGTTCACGG-3' }\end{array}$ \\
\hline HPRTf & 5'-TGTAATGACCAGTCAACAGGG-3' \\
\hline HPRTr & 5'-TGCGACCTTGACCATCTTTG-3' \\
\hline B2Mf & 5'-TCTTTCAGCAAGGACTGGTC-3' \\
\hline B2Mr & 5'-GGCATCTTCAAACCTCCATG-3' \\
\hline TBPf & 5'-CGGAGAGTTCTGGGATTGTAC-3' \\
\hline TBPr & 5'-GTGGTTCGTGGCTCTCTTAT-3' \\
\hline TFRCf & 5'-TCCTTGCATATTCTGGAATCCC-3' \\
\hline TFRCr & 5'-ATCACGAACTGACCAGCG-3' \\
\hline siLINC00493 & $\begin{array}{l}\text { 5'-GGCGUACCCAUGUAUCGAAAUdTdT-3' } \\
\text { 3'-dTdTCCGCAUGGGUACAUAGCUUUA-5' }\end{array}$ \\
\hline siControl & $\begin{array}{l}\text { 5'-AGGUAGUGUAAUCGCCUUGdTdT-3' } \\
\text { 3'-dTdTUCCAUCACAUUAGCGGAAC-5' }\end{array}$ \\
\hline FAM-control & $\begin{array}{l}\text { 5'-FAM-AGGUCGAACUACGGGUCAAdTdC-3' }^{\prime} \\
3^{\prime} \text {-dGdAUCCAGCUUGAUGCCCAGUU-FAM-5' }\end{array}$ \\
\hline
\end{tabular}




\subsection{Rapid Amplification of cDNA Ends (RACE)}

Total RNA from HEK293T, HeLa cells and human primary skin fibroblasts was extracted with ExtractRNA reagent (Evrogen, Moscow, Russia) according to the manufacturer's instruction. cDNA synthesis and rapid amplification of cDNA ends were performed using Mint RACE cDNA amplification kit (Evrogen, Moscow, Russia) according to the manufacturer's instruction. Primer sequences used for RACE are presented in Table 1. PCR products were analyzed by electrophoresis in $1 \%$ agarose gel. Then, $5^{\prime}$ - and $3^{\prime}$-RACE fragments were cloned into pGEM-T Easy vector (Promega, Madison, WI, USA). Ten random clones with inserts were obtained and sequenced.

\subsection{Subcellular RNA Localization}

Soft lysis method was used for subcellular fractionation [74]. HEK293T cells were detached by treatment with $1 \times$ Trypsin, transferred into $1.5 \mathrm{~mL}$ tubes and centrifuged at room temperature, $168 \times g$ for $5^{\prime}$. The pellet was lysed with $175 \mu \mathrm{L} / 10^{6}$ cells of cold RLN1 solution ( $50 \mathrm{mM}$ Tris $\mathrm{HCl} \mathrm{pH} 8,140 \mathrm{mM} \mathrm{NaCl}, 1.5 \mathrm{mM} \mathrm{MgCl}_{2}, 0.5 \%$ NP-40, RNasin Plus RNase Inhibitor, Promega, Madison, WI, USA) and incubated $5^{\prime}$ on ice. Next, the suspension was centrifuged at $4{ }^{\circ} \mathrm{C} 300 \times g$ for $2^{\prime}$ and the supernatant, corresponding to the cytoplasmic fraction, was transferred into a new tube and stored on ice. The pellet containing nuclei was lysed with $175 \mu \mathrm{L} / 10^{6}$ cells of cold RLN2 solution ( $50 \mathrm{mM}$ Tris $\mathrm{HCl}$ $\mathrm{pH}$ 8, $500 \mathrm{mM} \mathrm{NaCl}, 1.5 \mathrm{mM} \mathrm{MgCl}_{2}, 0.5 \%$ NP-40, RNasin Plus RNase Inhibitor, Promega, Madison, WI, USA) and incubated on ice for $5 \mathrm{~min}$. The suspension was centrifuged at $4{ }^{\circ} \mathrm{C} 16,360 \times g$ for $2^{\prime}$ and the supernatant, corresponding to the nuclear-soluble fraction, was transferred into a new tube and stored on ice. The remaining pellet corresponded to the chromatin-associated fraction. The ratio of target RNA in each fraction to total RNA was estimated using RT-qPCR. All experiments were performed in triplicate.

\subsection{LINC00493 Knockdown}

For LINC00493 knockdown, siRNA was designed using in-house software. Knockdown experiments were conducted as described in Vyakhireva et al. [75]. Briefly, $5 \times 10^{3}$ cells were seed in 96-well plates overnight and transfected with siRNA using METAFECTENE ${ }^{\circledR}$ (Biontex, Munich, Germany) according to the manufacturer's instructions. After $24 \mathrm{~h}$, the transfection efficiency of siRNA was evaluated by flow cytometry using FAM-labeled nonspecific siRNA (Table 1). Nonspecific siControl was used as a negative control.

For cell proliferation assay, cells were seeded to a density of $1 \times 10^{3}$ cells/well in six 96-well plates, and after that, knockdown was provided.

For cell migration assay, cells were seeded to a density of $10 \times 10^{3}$ cells/well in 96-well plates, and after that, knockdown was provided.

\subsection{LINC00493 Overexpression Experiments}

The LINC00493 transcript was amplified using HEK293T cDNA and Clon-F-HindIII and Clon-R-XholI primers. Firstly, the A-tailed fragment PCR products were directly ligated into the pGEM $^{\circledR}$-T Easy Vector (Promega, Madison, WI, USA). Clone containing the long isoform of LINC00493 was selected by Sanger sequencing. This clone was used to reclone inserts into HindIII/XholI sites of pcDNA3.1-GFP vector and obtain pcDNA3.1GFP-LINC0043 construction. To introduce mutation into the SMIM26 ORF start-codon we used the Single-Primer Site-Directed Mutagenesis Method [76]. The primers used for cloning and mutagenesis are listed in Table 1. Empty pcDNA3.1-GFP vector was used as control.

Cells were seed in 24-well plates overnight before transfection. Cells were transfected using Lipofectamine ${ }^{\mathrm{TM}} 3000$ (Invitrogen, Carlsbad, CA, USA) according to the manufacturer's instructions. The transfection efficiency was evaluated by flow cytometry $24 \mathrm{~h}$ after transfection.

For cell proliferation assay, transfected cells ( $24 \mathrm{~h}$ after transfection) were harvested and seeded to a density of $1 \times 10^{3}$ cells/well in six 96-well plates. 


\subsection{Cell Proliferation and Migration Assays}

Cell proliferation was investigated using MTT (3-[4,5-dimethylthiazol-2-yl]-2,5 diphenyl tetrazolium bromide) (Promega, Madison, WI, USA) assay. The protocol for the MTT assay was based on [75].

At 24, 48, 72, 96 and 120 h post transfection efficiency estimation, MTT working solution $(5 \mathrm{mg} / \mathrm{mL}$ MTT in PBS pH 7.4.) was added to each well (final concentration $0.5 \mathrm{mg} / \mathrm{mL}$ ) and incubated for $3 \mathrm{~h}$ at $37^{\circ} \mathrm{C}$. After incubation, the media was removed, and formazan pellets in each well were dissolved in $200 \mu \mathrm{L}$ DMSO, and optical density (OD) was measured at 570 and $670 \mathrm{~nm}$ (for background signals). All the experiments were carried out in three biological and five technical replicates. Statistical analysis was carried out using the paired Mann-Whitney U Test.

Cell migration capability was measured by wound-healing assay at $24 \mathrm{~h}$ post transfection. Cell monolayers were scraped with sterile $200 \mu \mathrm{L}$ pipette tips. At $0,2,4,6,8$ and $12 \mathrm{~h}$ after wounding, 1 field/well was visualized by microscopy. Images were analyzed using the Image J program (National Institutes of Health). Changes in the remaining wound area were measured relative to total wound square at $0 \mathrm{~h}$. All the experiments were carried out at three biological and five technical replicates. Statistical analysis was carried out using the paired Mann-Whitney U Test.

Supplementary Materials: The following are available online at https://www.mdpi.com/article/10 $.3390 /$ ijms22168477/s1.

Author Contributions: Conceptualization, M.S. and A.F.; methodology, M.S. and A.F.; formal analysis, D.K. and P.S.; investigation, D.K., P.S. and I.V.; writing-original draft preparation, D.K.; writing-review and editing, D.K., P.S., I.V., A.F. and M.S.; visualization, D.K. All authors have read and agreed to the published version of the manuscript.

Funding: The research was carried out within the state assignment of the Ministry of Science and Higher Education of the Russian Federation for RCMG.

Institutional Review Board Statement: Not applicable.

Informed Consent Statement: Not applicable.

Data Availability Statement: The datasets used and/or analyzed during the current study are available from the corresponding author on reasonable request.

Conflicts of Interest: The authors declare no conflict of interest.

\section{References}

1. Frankish, A.; Diekhans, M.; Ferreira, A.M.; Johnson, R.; Jungreis, I.; Loveland, J.; Mudge, J.M.; Sisu, C.; Wright, J.; Armstrong, J.; et al. Gencode reference annotation for the human and mouse genomes. Nucleic Acids Res. 2019, 47, D766-D773. [CrossRef]

2. Hon, C.C.; Ramilowski, J.A.; Harshbarger, J.; Bertin, N.; Rackham, O.J.; Gough, J.; Denisenko, E.; Schmeier, S.; Poulsen, T.M.; Severin, J.; et al. An atlas of human long non-coding RNAs with accurate 5' ends. Nature 2017, 543, 199-204. [CrossRef]

3. Dykes, I.M.; Emanueli, C. Transcriptional and Post-transcriptional Gene Regulation by Long Non-coding RNA. Genom. Proteom. Bioinform. 2017, 15, 177-186. [CrossRef]

4. St Laurent, G.; Wahlestedt, C.; Kapranov, P. The Landscape of long noncoding RNA classification. Trends Genet. TIG 2015, 31, 239-251. [CrossRef]

5. Panni, S.; Lovering, R.C.; Porras, P.; Orchard, S. Non-coding RNA regulatory networks. Biochim. Biophys. Acta Gene Regul. Mech. 2020, 1863, 194417. [CrossRef] [PubMed]

6. Cai, X.; Cullen, B.R. The imprinted H19 noncoding RNA is a primary microRNA precursor. RNA 2007, 13, 313-316. [CrossRef] [PubMed]

7. Pandey, R.R.; Mondal, T.; Mohammad, F.; Enroth, S.; Redrup, L.; Komorowski, J.; Nagano, T.; Mancini-Dinardo, D.; Kanduri, C. Kcnq1ot1 antisense noncoding RNA mediates lineage-specific transcriptional silencing through chromatin-level regulation. Mol. Cell 2008, 32, 232-246. [CrossRef]

8. Orom, U.A.; Derrien, T.; Beringer, M.; Gumireddy, K.; Gardini, A.; Bussotti, G.; Lai, F.; Zytnicki, M.; Notredame, C.; Huang, Q.; et al. Long noncoding RNAs with enhancer-like function in human cells. Cell 2010, 143, 46-58. [CrossRef] [PubMed]

9. Orom, U.A.; Derrien, T.; Guigo, R.; Shiekhattar, R. Long noncoding RNAs as enhancers of gene expression. Cold Spring Harb. Symp. Quant. Biol. 2010, 75, 325-331. [CrossRef] 
10. Gong, C.; Maquat, L.E. lncRNAs transactivate STAU1-mediated mRNA decay by duplexing with 3' UTRs via Alu elements. Nature 2011, 470, 284-288. [CrossRef]

11. Wang, Y.; Xu, Z.; Jiang, J.; Xu, C.; Kang, J.; Xiao, L.; Wu, M.; Xiong, J.; Guo, X.; Liu, H. Endogenous miRNA sponge lincRNA-RoR regulates Oct4, Nanog, and Sox2 in human embryonic stem cell self-renewal. Dev. Cell 2013, 25, 69-80. [CrossRef] [PubMed]

12. Keniry, A.; Oxley, D.; Monnier, P.; Kyba, M.; Dandolo, L.; Smits, G.; Reik, W. The H19 lincRNA is a developmental reservoir of miR-675 that suppresses growth and Igf1r. Nat. Cell Biol. 2012, 14, 659-665. [CrossRef]

13. Liu, S.J.; Horlbeck, M.A.; Cho, S.W.; Birk, H.S.; Malatesta, M.; He, D.; Attenello, F.J.; Villalta, J.E.; Cho, M.Y.; Chen, Y.; et al. CRISPRi-based genome-scale identification of functional long noncoding RNA loci in human cells. Science 2017, 355. [CrossRef]

14. Sparber, P.; Filatova, A.; Khantemirova, M.; Skoblov, M. The role of long non-coding RNAs in the pathogenesis of hereditary diseases. BMC Med. Genom. 2019, 12, 42. [CrossRef]

15. Bao, Z.; Yang, Z.; Huang, Z.; Zhou, Y.; Cui, Q.; Dong, D. LncRNADisease 2.0: An updated database of long non-coding RNA-associated diseases. Nucleic Acids Res. 2019, 47, D1034-D1037. [CrossRef]

16. Lorenzen, J.M.; Thum, T. Long noncoding RNAs in kidney and cardiovascular diseases. Nat. Rev. Nephrol. 2016, 12, 360-373. [CrossRef] [PubMed]

17. Chen, Y.; Zhou, J. LncRNAs: Macromolecules with big roles in neurobiology and neurological diseases. Metab. Brain Dis. 2017, 32, 281-291. [CrossRef] [PubMed]

18. Chi, Y.; Wang, D.; Wang, J.; Yu, W.; Yang, J. Long Non-Coding RNA in the Pathogenesis of Cancers. Cells 2019, 8, 1015. [CrossRef]

19. St Laurent, G.; Vyatkin, Y.; Kapranov, P. Dark matter RNA illuminates the puzzle of genome-wide association studies. BMC Med. 2014, 12, 97. [CrossRef] [PubMed]

20. Hindorff, L.A.; Sethupathy, P.; Junkins, H.A.; Ramos, E.M.; Mehta, J.P.; Collins, F.S.; Manolio, T.A. Potential etiologic and functional implications of genome-wide association loci for human diseases and traits. Proc. Natl. Acad. Sci. USA 2009, 106, 9362-9367. [CrossRef]

21. Chew, G.L.; Pauli, A.; Rinn, J.L.; Regev, A.; Schier, A.F.; Valen, E. Ribosome profiling reveals resemblance between long non-coding RNAs and 5' leaders of coding RNAs. Development 2013, 140, 2828-2834. [CrossRef]

22. Aspden, J.L.; Eyre-Walker, Y.C.; Phillips, R.J.; Amin, U.; Mumtaz, M.A.; Brocard, M.; Couso, J.P. Extensive translation of small Open Reading Frames revealed by Poly-Ribo-Seq. eLife 2014, 3, e03528. [CrossRef]

23. Bazzini, A.A.; Johnstone, T.G.; Christiano, R.; Mackowiak, S.D.; Obermayer, B.; Fleming, E.S.; Vejnar, C.E.; Lee, M.T.; Rajewsky, N.; Walther, T.C.; et al. Identification of small ORFs in vertebrates using ribosome footprinting and evolutionary conservation. $E M B O$ J. 2014, 33, 981-993. [CrossRef]

24. Choi, S.W.; Kim, H.W.; Nam, J.W. The small peptide world in long noncoding RNAs. Brief. Bioinform. 2019, 20 , 1853-1864. [CrossRef]

25. Stein, C.S.; Jadiya, P.; Zhang, X.; McLendon, J.M.; Abouassaly, G.M.; Witmer, N.H.; Anderson, E.J.; Elrod, J.W.; Boudreau, R.L. Mitoregulin: A lncRNA-Encoded Microprotein that Supports Mitochondrial Supercomplexes and Respiratory Efficiency. Cell Rep. 2018, 23, 3710-3720.e3718. [CrossRef]

26. Chugunova, A.; Loseva, E.; Mazin, P.; Mitina, A.; Navalayeu, T.; Bilan, D.; Vishnyakova, P.; Marey, M.; Golovina, A.; Serebryakova, M.; et al. LINC00116 codes for a mitochondrial peptide linking respiration and lipid metabolism. Proc. Natl. Acad. Sci. USA 2019, 116, 4940-4945. [CrossRef]

27. Konina, D.O.; Filatova, A.Y.; Skoblov, M.Y. LINC01420 RNA structure and influence on cell physiology. BMC Genom. 2019, 20, 298. [CrossRef] [PubMed]

28. Haeussler, M.; Zweig, A.S.; Tyner, C.; Speir, M.L.; Rosenbloom, K.R.; Raney, B.J.; Lee, C.M.; Lee, B.T.; Hinrichs, A.S.; Gonzalez, J.N.; et al. The UCSC Genome Browser database: 2019 update. Nucleic Acids Res. 2019, 47, D853-D858. [CrossRef] [PubMed]

29. Derrien, T.; Johnson, R.; Bussotti, G.; Tanzer, A.; Djebali, S.; Tilgner, H.; Guernec, G.; Martin, D.; Merkel, A.; Knowles, D.G.; et al. The GENCODE v7 catalog of human long noncoding RNAs: Analysis of their gene structure, evolution, and expression. Genome Res. 2012, 22, 1775-1789. [CrossRef]

30. FANTOM Consortium; The RIKEN PMI; CLST (DGT); Forrest, A.R.; Kawaji, H.; Rehli, M.; Baillie, J.K.; de Hoon, M.J.; Haberle, V.; Lassmann, T.; et al. A promoter-level mammalian expression atlas. Nature 2014, 507, 462-470. [CrossRef] [PubMed]

31. Uhlen, M.; Fagerberg, L.; Hallstrom, B.M.; Lindskog, C.; Oksvold, P.; Mardinoglu, A.; Sivertsson, A.; Kampf, C.; Sjostedt, E.; Asplund, A.; et al. Proteomics. Tissue-based map of the human proteome. Science 2015, 347, 1260419. [CrossRef]

32. Michel, A.M.; Kiniry, S.J.; O'Connor, P.B.F.; Mullan, J.P.; Baranov, P.V. GWIPS-viz: 2018 update. Nucleic Acids Res. 2018, 46, D823-D830. [CrossRef]

33. Kiniry, S.J.; O'Connor, P.B.F.; Michel, A.M.; Baranov, P.V. Trips-Viz: A transcriptome browser for exploring Ribo-Seq data. Nucleic Acids Res. 2019, 47, D847-D852. [CrossRef] [PubMed]

34. Yang, J.; Anishchenko, I.; Park, H.; Peng, Z.; Ovchinnikov, S.; Baker, D. Improved protein structure prediction using predicted interresidue orientations. Proc. Natl. Acad. Sci. USA 2020, 117, 1496-1503. [CrossRef]

35. Ramilowski, J.A.; Yip, C.W.; Agrawal, S.; Chang, J.C.; Ciani, Y.; Kulakovskiy, I.V.; Mendez, M.; Ooi, J.L.C.; Ouyang, J.F.; Parkinson, N.; et al. Functional annotation of human long noncoding RNAs via molecular phenotyping. Genome Res. 2020, 30 1060-1072. [CrossRef] 
36. Jin, Y.; Zhang, B.; Lu, J.; Song, Y.; Wang, W.; Zhang, W.; Shao, F.; Gong, M.; Wang, M.; Liang, X.; et al. Long noncoding RNA PM maintains cerebellar synaptic integrity and Cbln1 activation via Pax6/Mll1-mediated H3K4me3. PLoS Biol. 2021, 19 , e3001297. [CrossRef]

37. Mukherjee, N.; Calviello, L.; Hirsekorn, A.; de Pretis, S.; Pelizzola, M.; Ohler, U. Integrative classification of human coding and noncoding genes through RNA metabolism profiles. Nat. Struct. Mol. Biol. 2017, 24, 86-96. [CrossRef] [PubMed]

38. Yeasmin, F.; Imamachi, N.; Tanu, T.; Taniue, K.; Kawamura, T.; Yada, T.; Akimitsu, N. Identification and analysis of short open reading frames (sORFs) in the initially annotated noncoding RNA LINC00493 from human cells. J. Biochem. 2021, 169, 421-434. [CrossRef] [PubMed]

39. Zhang, S.; Reljić, B.; Liang, C.; Kerouanton, B.; Francisco, J.C.; Peh, J.H.; Mary, C.; Jagannathan, N.S.; Olexiouk, V.; Tang, C.; et al. Mitochondrial peptide BRAWNIN is essential for vertebrate respiratory complex III assembly. Nat. Commun. 2020, 11. [CrossRef]

40. Karczewski, K.J.; Francioli, L.C.; Tiao, G.; Cummings, B.B.; Alfoldi, J.; Wang, Q.; Collins, R.L.; Laricchia, K.M.; Ganna, A.; Birnbaum, D.P.; et al. The mutational constraint spectrum quantified from variation in 141,456 humans. Nature 2020, 581, 434-443. [CrossRef]

41. Nam, J.W.; Choi, S.W.; You, B.H. Incredible RNA: Dual Functions of Coding and Noncoding. Mol. Cells 2016, 39, 367-374. [CrossRef] [PubMed]

42. Rubtsova, M.; Naraykina, Y.; Vasilkova, D.; Meerson, M.; Zvereva, M.; Prassolov, V.; Lazarev, V.; Manuvera, V.; Kovalchuk, S.; Anikanov, N.; et al. Protein encoded in human telomerase RNA is involved in cell protective pathways. Nucleic Acids Res. 2018, 46, 8966-8977. [CrossRef]

43. Spencer, H.L.; Sanders, R.; Boulberdaa, M.; Meloni, M.; Cochrane, A.; Spiroski, A.M.; Mountford, J.; Emanueli, C.; Caporali, A.; Brittan, M.; et al. The LINC00961 transcript and its encoded micropeptide, small regulatory polypeptide of amino acid response, regulate endothelial cell function. Cardiovasc. Res. 2020, 116, 1981-1994. [CrossRef] [PubMed]

44. Stevens, S.G.; Brown, C.M. In silico estimation of translation efficiency in human cell lines: Potential evidence for widespread translational control. PLoS ONE 2013, 8, e57625. [CrossRef]

45. Li, J.H.; Liu, S.; Zhou, H.; Qu, L.H.; Yang, J.H. starBase v2.0: Decoding miRNA-ceRNA, miRNA-ncRNA and protein-RNA interaction networks from large-scale CLIP-Seq data. Nucleic Acids Res. 2014, 42, D92-D97. [CrossRef]

46. Lietman, S.A.; Yin, L.; Levine, M.A. SH3BP2 is an activator of NFAT activity and osteoclastogenesis. Biochem. Biophys. Res. Commun. 2008, 371, 644-648. [CrossRef] [PubMed]

47. Ullrich, S.; Munch, A.; Neumann, S.; Kremmer, E.; Tatzelt, J.; Lichtenthaler, S.F. The novel membrane protein TMEM59 modulates complex glycosylation, cell surface expression, and secretion of the amyloid precursor protein. J. Biol. Chem. 2010, 285, 20664-20674. [CrossRef]

48. Haase, M.; Fitze, G. HSP90AB1: Helping the good and the bad. Gene 2016, 575, 171-186. [CrossRef] [PubMed]

49. Bereshchenko, O.; Migliorati, G.; Bruscoli, S.; Riccardi, C. Glucocorticoid-Induced Leucine Zipper: A Novel Anti-inflammatory Molecule. Front. Pharmacol. 2019, 10, 308. [CrossRef]

50. Mascarenhas, R.; Dougherty, J.A.; Schoenberg, D.R. SMG6 cleavage generates metastable decay intermediates from nonsensecontaining beta-globin mRNA. PLoS ONE 2013, 8, e74791. [CrossRef] [PubMed]

51. Nicholson, P.; Josi, C.; Kurosawa, H.; Yamashita, A.; Muhlemann, O. A novel phosphorylation-independent interaction between SMG6 and UPF1 is essential for human NMD. Nucleic Acids Res. 2014, 42, 9217-9235. [CrossRef] [PubMed]

52. Jiang, Y.; Zhu, Y.; Liu, Z.J.; Ouyang, S. The emerging roles of the DDX41 protein in immunity and diseases. Protein Cell 2017, 8, 83-89. [CrossRef] [PubMed]

53. Yuan, X.; Zhang, M.; Ao, J.; Zhen, Z.; Gao, X.; Li, M. NUCKS1 is a novel regulator of milk synthesis in and proliferation of mammary epithelial cells via the mTOR signaling pathway. J. Cell. Physiol. 2019. [CrossRef] [PubMed]

54. Gong, J.; Shao, D.; Xu, K.; Lu, Z.; Lu, Z.J.; Yang, Y.T.; Zhang, Q.C. RISE: A database of RNA interactome from sequencing experiments. Nucleic Acids Res. 2018, 46, D194-D201. [CrossRef]

55. Paraskevopoulou, M.D.; Hatzigeorgiou, A.G. Analyzing MiRNA-LncRNA Interactions. Methods Mol. Biol. 2016, 1402, 271-286. [CrossRef]

56. Wang, C.; Zhou, B.; Liu, M.; Liu, Y.; Gao, R. miR-126-5p Restoration Promotes Cell Apoptosis in Cervical Cancer by Targeting Bcl212. Oncol. Res. 2017, 25, 463-470. [CrossRef]

57. Villain, G.; Poissonnier, L.; Noueihed, B.; Bonfils, G.; Rivera, J.C.; Chemtob, S.; Soncin, F.; Mattot, V. miR-126-5p promotes retinal endothelial cell survival through SetD5 regulation in neurons. Development 2018. [CrossRef]

58. Li, C.; Zhang, Y.; Zhao, W.; Cui, S.; Song, Y. miR-153-3p regulates progression of ovarian carcinoma in vitro and in vivo by targeting MCL1 gene. J. Cell. Biochem. 2019, 120, 19147-19158. [CrossRef]

59. Liu, Y.J.; Zhou, H.G.; Chen, L.H.; Qu, D.C.; Wang, C.J.; Xia, Z.Y.; Zheng, J.H. MiR-32-5p regulates the proliferation and metastasis of cervical cancer cells by targeting HOXB8. Eur. Rev. Med. Pharmacol. Sci. 2019, 23, 87-95. [CrossRef]

60. Ye, Z.; Shi, J.; Ning, Z.; Hou, L.; Hu, C.Y.; Wang, C. MiR-92b-3p inhibits proliferation and migration of C2C12 cells. Cell Cycle 2020, 19, 2906-2917. [CrossRef]

61. Wang, Y.; Chen, R.; Zhou, X.; Guo, R.; Yin, J.; Li, Y.; Ma, G. miR-137: A Novel Therapeutic Target for Human Glioma. Mol. Ther. Nucleic Acids 2020, 21, 614-622. [CrossRef]

62. Wei, H.; Yu, K.; Liu, Y.; Li, L.; Wang, G. Tumor expression of miR-448 is a prognostic marker in oral squamous cell carcinoma. BMC Cancer 2020, 20, 756. [CrossRef] [PubMed] 
63. Lou, Q.; Liu, R.; Yang, X.; Li, W.; Huang, L.; Wei, L.; Tan, H.; Xiang, N.; Chan, K.; Chen, J.; et al. miR-448 targets IDO1 and regulates CD8(+) T cell response in human colon cancer. J. Immunother. Cancer 2019, 7, 210. [CrossRef] [PubMed]

64. Liu, E.; Sun, H.; Wu, J.; Kuang, Y. MiR-92b-3p regulates oxygen and glucose deprivation-reperfusion-mediated apoptosis and inflammation by targeting TRAF3 in PC12 cells. Exp. Physiol. 2020, 105, 1792-1801. [CrossRef] [PubMed]

65. Tang, Z.; Kang, B.; Li, C.; Chen, T.; Zhang, Z. GEPIA2: An enhanced web server for large-scale expression profiling and interactive analysis. Nucleic Acids Res. 2019, 47, W556-W560. [CrossRef]

66. O'Leary, N.A.; Wright, M.W.; Brister, J.R.; Ciufo, S.; Haddad, D.; McVeigh, R.; Rajput, B.; Robbertse, B.; Smith-White, B.; Ako-Adjei, D.; et al. Reference sequence (RefSeq) database at NCBI: Current status, taxonomic expansion, and functional annotation. Nucleic Acids Res. 2016, 44, D733-D745. [CrossRef] [PubMed]

67. Cunningham, F.; Achuthan, P.; Akanni, W.; Allen, J.; Amode, M.R.; Armean, I.M.; Bennett, R.; Bhai, J.; Billis, K.; Boddu, S.; et al. Ensembl 2019. Nucleic Acids Res. 2019, 47, D745-D751. [CrossRef]

68. Noguchi, S.; Arakawa, T.; Fukuda, S.; Furuno, M.; Hasegawa, A.; Hori, F.; Ishikawa-Kato, S.; Kaida, K.; Kaiho, A.; KanamoriKatayama, M.; et al. FANTOM5 CAGE profiles of human and mouse samples. Sci. Data 2017, 4, 170112. [CrossRef] [PubMed]

69. Consortium, G.T. The Genotype-Tissue Expression (GTEx) project. Nat. Genet. 2013, 45, 580-585. [CrossRef]

70. Kall, L.; Krogh, A.; Sonnhammer, E.L. Advantages of combined transmembrane topology and signal peptide prediction-the Phobius web server. Nucleic Acids Res. 2007, 35, W429-W432. [CrossRef]

71. Viklund, H.; Bernsel, A.; Skwark, M.; Elofsson, A. SPOCTOPUS: A combined predictor of signal peptides and membrane protein topology. Bioinformatics 2008, 24, 2928-2929. [CrossRef] [PubMed]

72. Nugent, T.; Ward, S.; Jones, D.T. The MEMPACK alpha-helical transmembrane protein structure prediction server. Bioinformatics 2011, 27, 1438-1439. [CrossRef] [PubMed]

73. Ulintz, P.J.; Wu, W.; Gates, C.M. Bioinformatics Analysis of Whole Exome Sequencing Data. Methods Mol. Biol. 2019, 1881, 277-318. [CrossRef]

74. Cabianca, D.S.; Casa, V.; Bodega, B.; Xynos, A.; Ginelli, E.; Tanaka, Y.; Gabellini, D. A long ncRNA links copy number variation to a polycomb/trithorax epigenetic switch in FSHD muscular dystrophy. Cell 2012, 149, 819-831. [CrossRef]

75. Vyakhireva, J.V.; Filatova, A.Y.; Krivosheeva, I.A.; Skoblov, M.Y. siRNA-mediated gene silencing. Bull. RSMU 2017. [CrossRef]

76. Huang, Y.; Zhang, L. An In Vitro Single-Primer Site-Directed Mutagenesis Method for Use in Biotechnology. Methods Mol. Biol. 2017, 1498, 375-383. [CrossRef] [PubMed] 